protected by U.S. and International Trademark and Copyright laws. Permission for use is required. A license agreement is available from: MMAS Research LLC, 14725 NE 20th St., Bellevue WA 98007 or dmorisky@gmail.com.

Acknowledgement: Investigators and patients of APRiM study Disclosure of Interests: René-Marc Flipo Consultant for: Honoraria from Novartis as steering committe of this survey, Eric Senbel Consultant for: Nordic Pharma, Speakers bureau: Nordic Pharma, Sonia Tropé: None declared, Elena Zinovieva Employee of: Nordic Pharma, Agnès Courbeyrette Employee of: Nordic Pharma, Hélène Herman-Demars Employee of: Nordic Pharma

DOI: 10.1136/annrheumdis-2019-eular.3171

\section{FRI0149 DISEASE ACTIVITY IN ESCALATION OR DE- ESCALATION OF DOSAGE OF TOFACITINIB IN RHEUMATOID ARTHRITIS PATIENTS - THE FIRST RESULTS OF RUSSIAN NATIONAL REGISTER OF PATIENTS WITH RHEUMATOID ARTHRITIS TREATED WITH TOFACITINIB}

Inna Gaydukova ${ }^{1}$, V Mazurov ${ }^{1}$, Elizaveta Vasilenko ${ }^{1}$, Evgeniy Zhilyaev², Vyacheslav Poncratov ${ }^{3}$, Valentina Sorotskaya ${ }^{4}$, Galina Lukina ${ }^{5}$, Oxana Fomina ${ }^{6}$, Aida Babaeva ${ }^{7}$, N Lapkina ${ }^{8}$, Anna Misiyuk ${ }^{9}$, A Pavlova ${ }^{10}$, Evgeny Nasonov ${ }^{9}$. ${ }^{1}$ North-Western State Medical University, St. Petersburg, Russian Federation; ${ }^{2}$ European Medical Center, Moscow, Russian Federation; ${ }^{3}$ Kursk State Medical University, Kursk, Russian Federation; ${ }^{4}$ Tula State Medical University, Tula, Russian Federation; ${ }^{5}$ Moscow Clinical Scientific Center, Moscow, Russian Federation; ${ }^{6}$ Reginal Hospital, Amur, Amur, Russian Federation; ${ }^{7}$ Volgograd State Medical University, Volgograd, Russian Federation; ${ }^{8}$ Yaroslavl State Medical University, Yaroslavl, Russian Federation; ${ }^{9}$ VA Nasonova Research Institute of Rheumatology, Moscow, Russian Federation; ${ }^{10}$ Clinical Hospital Republic of Buryatia, Ulan-Ude, Russian Federation

Background: In previous studies tofacitinib (TF) had demonstrated efficacy of two dosages (10 and $20 \mathrm{mg} / \mathrm{day}$ ) in patients with rheumatoid arthritis (RA). However, the expected results of switching of 'TF' dosages are unknown.

Objectives: The aim of the study was to evaluate the results of switching of TF's dosages in RA patients.

Methods: Were analyzed the data from Russian national register of patients with RA treated with TF (tofacitinib). 415 patients were involved in the register (aug 2018). In statistical analysis were included data from 41 patients with RA (EULAR 2010), who switched dosage of TF at visit 3 and had complete clinical and laboratory data from 5 consecutive visits with an interval of 3 months between the visits. Demographical (age, sex) data, disease activity data DAS28 (Disease activity score), C-reactive protein level were collected, table 1 . Changes in disease activity were calculated to patients with switching of the tofa's dosage (the visit before and after the switching).

Results: $1.28(68 \%)$ of patients were treated with NSAIDs, $24(50 \%)$ with $5-10 \mathrm{mg}$ of prednisolone, 34 (82.9) - with methotrexate (10-25 mg/week), biologics $-5(4.2 \%)$.

Table 1. Baseline characteristics of the patients with RA included in the study $(n=41)$

\begin{tabular}{lc}
\hline Parameter & Characteristics \\
\hline Male, $\mathrm{n}(\%)$ & $10(24.3)$ \\
Caucasians, $\mathrm{n}(\%)$ & $41(100)$ \\
Asians, $\mathrm{n}(\%)$ & $0(0)$ \\
Age of disease onset, years (mean $\pm \mathrm{SD})$ & $40.1 \pm 10.5$ \\
Symptoms duration, month (mean $\pm \mathrm{SD})$ & $98.7 \pm 87.1$ \\
Positive rheumatoid factor, $\mathrm{n}(\%)$ & $32(78)$ \\
Positive antibodies to cyclic citrullinated peptide (anti-CCP), $\mathrm{n}$ & $37(90.2)$ \\
$(\%)$ & \\
BMl, $\mathrm{kg} / \mathrm{m}^{2}$ (mean $\left.\pm \mathrm{SD}\right)$ & $25.12 \pm 5.98$ \\
Smokers (current and in the anamnesis), $\mathrm{n}(\%)$ & $33(80)$ \\
\hline
\end{tabular}

From 41 persons with RA 32 patients, who never achieved low disease activity (DAS28<3.2) or remission (DAS28<2.6) elevated the dosage of tofa from 10 to $20 \mathrm{mg} /$ day and 9 patients with DAS28<3.2 decreased the dosage from 20 to $10 \mathrm{mg} /$ day.

After escalation of TF dosage DAS28 decreased from $5.42 \pm 1.22$ to 4.22 $\pm 1.22(\mathrm{p}<0.00), \mathrm{n}=32$. In 10 patients escalation lead to DAS28-remission (DAS28 <2.6) and in 12 patients - to low disease activity (DAS28<3.2).
10 patients had no clinical or laboratory response on escalation of TF dosage. Interestingly, that responders before escalation of dosage had mean DAS28 $3.54(\min 3.2$ - $\max 4.9)$ and non-responders - 5.54 ( $\mathrm{min}$ 5.3-max 6.9), $\mathrm{p}<0.000$

De-escalation of the dosage from 20 to $10 \mathrm{mg} /$ day was not associated with significant changes of DAS28 (1.99 \pm 1.25 increased to $2.1 \pm 0.96$ respectively, $\mathrm{p}=0.82$ ).

Conclusion: Escalation of dosage of TF in RA lead to improvement of the disease activity in non-complete responders, who achieved DAS 28 3.2-5.1, but not in patients with absence of any response (DAS28 before escalation 5.3-6.9). De-escalation of TF' dosage in patients with DAS28 < 2.6 dose not lead to significant changes of RA's activity.

\section{REFERENCES}

[1] Fleischmann R, et al. Lancet. 2017 Jul 29;390(10093):457-468. doi: $10.1016 / \mathrm{S} 0140-6736(17) 31618-5$

Acknowledgement: Pfizer is sponsor of register Technical support ASTON group

Disclosure of Interests: Inna Gaydukova Grant/research support from: JSC BIOCAD, Speakers bureau: paiment from Pfizer, Novartis, Abbvie, Biocad, Selgene, MSD, Sanofy does not exceed 10000 euros, V Mazurov Grant/research support from: JSC BIOCAD, Elizaveta Vasilenko: None declared, Evgeniy Zhilyaev: None declared, Vyacheslav Poncratov: None declared, Valentina Sorotskaya: None declared, Galina Lukina: None declared, Oxana Fomina: None declared, Aida Babaeva: None declared, N Lapkina: None declared, Anna Misiyuk: None declared, A Pavlova: None declared, Evgeny Nasonov: None declared DOI: 10.1136/annrheumdis-2019-eular.6265

\section{FRI0150 GS-9876, A NOVEL, HIGHLY SELECTIVE, SYK INHIBITOR IN PATIENTS WITH ACTIVE RHEUMATOID ARTHRITIS: SAFETY, TOLERABILITY AND EFFICACY RESULTS OF A PHASE 2 STUDY}

Alan Kivitz ${ }^{1}$, Daksha Mehta ${ }^{2}$, Franziska Matzkies ${ }^{3}$, Afsaneh Mozaffarian ${ }^{3}$, Rebecca Kunder ${ }^{3}$, Julie A. DI Paolo ${ }^{3}$, Neelufar Mozaffarian ${ }^{3}$, Sean Hsueh ${ }^{3}$ Jiyun $\mathrm{Kim}^{3}$, Wendy Jiang ${ }^{3}$, Lin Liu' ${ }^{3}$, John Sundy ${ }^{3}$, Mark C. Genovese ${ }^{4} .{ }^{1}$ Altoona Center for Clinical Research, Duncansville, United States of America; ${ }^{2}$ Center for Arthritis and Osteoporosis, Elizabethtown, United States of America; ${ }^{3}$ Gilead Sciences, Inc., Foster City, United States of America; ${ }^{4}$ Stanford University Medical Center, Palo Alto, United States of America

Background: Spleen tyrosine kinase (SYK) mediates immunoreceptor sig naling and is essential in activation of cells including B lymphocytes, monocytes, macrophages, dendritic cells, and osteoclasts. SYK may play an important role in the initiation and progression of autoimmune diseases, including rheumatoid arthritis (RA) and lupus. GS-9876 is a novel, potent, highly selective oral inhibitor of SYK in phase 2 trials for autoimmune diseases.

Objectives: To evaluate the efficacy, safety, and pharmacokinetics of GS9876, and its impact on biomarkers relevant to RA as well as the SYK and JAK pathways.

Methods: Patients with active RA with prior inadequate response to methotrexate (MTX) or a biologic antirheumatic drug were randomized 1:1:1:1 to receive GS-9876 $30 \mathrm{mg}$, GS-9876 $10 \mathrm{mg}$, selective JAK1 inhibitor filgotinib (FIL) $200 \mathrm{mg}$, or matching placebo (PBO) once daily for 12 weeks on a stable background of oral MTX. The primary endpoint for GS-9876 was the change in DAS28(CRP) at week 12. Pharmacokinetics and various biomarkers were evaluated at several time points, including VectraDA and stimulation of whole blood in TruCulture (MyriadRBM) tubes.

Results: A total of 83 patients received the study drug and 79 completed the study. Fourteen patients $(16.9 \%)$ were male and $69(83.1 \%)$ were female. The majority were white $(77,92.8 \%)$. The mean (SD) age at baseline (BL) was 55 (11.5) years (range 18 to 73). The primary and secondary endpoints are reported in Table 1. For DAS28(CRP), the mean (SD) at BL was 5.75 (0.961) with a median of 5.69 ; a statistically significant reduction at week 12 was observed only in patients receiving FIL as compared to PBO (Table 1). Adverse events (AEs) were reported across all groups $(37.5 \%$ in the combined GS- 9876 arms, $38.1 \%$ in $\mathrm{FIL}$, $40.9 \%$ in PBO). No deaths or serious AEs were reported. Plasma exposures of all study drugs were comparable to those observed in healthy subjects and historical data. Ex vivo stimulated whole blood identified differential responses between GS-9876 and PBO. 
Table 1. Key endpoints at week 12

\begin{tabular}{|c|c|c|c|}
\hline & $\begin{array}{c}\text { DAS28(CRP) })^{a} \\
\text { (mean change from BL to } \\
\text { week 12) }\end{array}$ & $\begin{array}{c}\text { ACR20/50/70 } \\
(\% \text { achieving at } \\
\text { week 12) }\end{array}$ & $\begin{array}{c}\mathrm{HAQ}-\mathrm{DI} \mathrm{b}^{\mathrm{b}} \\
\text { (mean change from } \mathrm{BL} \text { to } \\
\text { week 12) }\end{array}$ \\
\hline PBO & $-1.36(1.044)$ & 40.9/22.7/13.6 & $-0.39(0.389)$ \\
\hline $\begin{array}{l}\text { GS-9876 } 10 \\
\mathrm{mg}\end{array}$ & $-0.78(1.119)$ & $25.0 / 20.0 / 15.0$ & $-0.18(0.800)$ \\
\hline $\begin{array}{l}\text { GS-9876 } 30 \\
\mathrm{mg}\end{array}$ & $-1.26(1.276)$ & $35.0 / 20.0 / 5.0$ & $-0.46(0.480)$ \\
\hline FIL 200 mg & $-2.46(1.242) ;{ }^{*} \mathrm{p}=0.002$ & 81.0/47.6/38.1 & $-0.70(0.649)$ \\
\hline
\end{tabular}

a Primary endpoint; ${ }^{b}$ Secondary endpoint; * ${ }^{*}$ (compared to PBO).

Conclusion: Clinical efficacy of GS-9876 in RA was not observed, but GS-9876 was safe and well-tolerated over a 12-week period in patients with RA on MTX. FIL showed favorable safety and clinical efficacy consistent with prior data, validating the study concept and design. Additionally, biomarker changes with GS-9876 support the continuation of studies in lupus-related diseases.

\section{REFERENCES:}

[1] Kivitz AJ, et al. ACR 2018. Abstract 2518.

Disclosure of Interests: Alan Kivitz Shareholder of: Novartis, Consultant for: Abbvie, Janssen, Pfizer, UCB, Genzyme, Sanofi, Regeneron, Boehringer Ingelheim, Sun Pharma Advanced Research, Flexion., Paid instructor for: Celgene, Horizon, Merck, Novartis, Pfizer, Genzyme, Sanofi, Regeneron, Speakers bureau: Celgene, Horizon, Merck and Genetech, Flexion, Daksha Mehta: None declared, Franziska Matzkies Shareholder of: Gilead, Employee of: Gilead, Afsaneh Mozaffarian Employee of: Gilead Sciences, Inc., Rebecca Kunder Shareholder of: Gilead Sciences, Inc., Julie A. Di Paolo Shareholder of: Gilead Sciences, Inc., Employee of: Gilead Sciences, Inc., Neelufar Mozaffarian Shareholder of: Gilead, Employee of: Gilead, Sean Hsueh Shareholder of: Gilead Sciences, Inc., Employee of: Gilead Sciences, Inc., JiYun Kim Shareholder of: Gilead Sciences, Inc., Employee of: Bayer Healthcare, LLC, Gilead Sciences, Inc., Wendy Jiang Shareholder of: Gilead Sciences, Inc., Employee of: Gilead Sciences, Inc., Lin Liu Shareholder of: Gilead Sciences, Inc., Employee of: Gilead Sciences, Inc., John Sundy Shareholder of: Gilead Sciences, Inc., Employee of: Gilead Sciences, Inc., Mark C. Genovese Grant/research support from: Sanofi/Genzyme, Genentech/Roche, RPharm, Consultant for: Sanofi/Genzyme, Genentech/Roche, RPharm DOI: 10.1136/annrheumdis-2019-eular.2144

\section{FRI0151 THE RELATIONSHIP BETWEEN THE EFFECTIVENESS OF METHOTREXATE (MTX) IN RHEUMATOID ARTHRITIS (RA) AND MTX POLYGLUTAMATES LEVELS (MTXPGS) IN RED BLOOD CELLS BY TANDEM CHROMATOMASS SPECTROMETRY (PILOT STUDY)}

Galina Gridneva ${ }^{1}$, Yury Muraviev ${ }^{1}$, Alexander Lila ${ }^{1}$, Natalia Baymeeva ${ }^{2}{ }^{1}$ V.A. Nasonova Research Institute of Rheumatology, Moscow, Russian Federation; ${ }^{2}$ Mental Health Research Center., Moscow, Russian Federation

Background: Therapeutic control of the level of MTXPGs in erythrocytes may be an objective marker of its effective dose in RA treatment.

Objectives: To evaluate the relationship between the level of MTXPGs in erythrocytes and the effectiveness of the dose of MT used by RA patients.

Methods: The study included 60 random selected RA patients over the age of 18,16 men and 44 women. The diagnosis in all cases met the criteria of ACR/EULAR 2010. All pts received MTX at a constant dose of at least $20 \mathrm{mg}$ per week subcutaneously for at least the last 12 weeks. Patients were divided into 2 groups depending on the presence (group 1 , $n=30$ ) or absence (group 2, n = 30) of the therapeutic effect of MTX, according to the criteria of the EULAR response to therapy. The groups were comparable in age, sex, alcohol intake, smoking, body mass index (BMI), ACPP-positivity, incidence of unwanted reactions to MTX, single dose of MTX, duration of MTX treatment course. The groups differed in duration of the disease at the beginning of the current course of continuous therapy: $5.5[2.0,12.0]$ months in group 1 and $12.0[3.0,60.0]$ months in group 2; in group 2 patients received glucocorticoids (GK) orally $17(57 \%)$ against $9(30 \%)$ in group 1. Blood sampling was performed no later than 36 hours after the last administration of methotrexate. From each patient $2 \mathrm{ml}$ of hemolysed blood were examined using an Agilent 6410 chromatograph (Agilent Technologies) - a quantitative measurement of methotrexate polyglutamate by liquid chromatographyspectrometry.
Results: It was established that the levels of total MTXPG and MTXPG1,2,3,5 in erythrocytes did not depend on the effectiveness of MTX, the dose of which was comparable in all patients. At the same time, the level of MTXPG4 was significantly higher $(p=0.023)$ in patients of group $1(26.4 \pm 6.1 \mathrm{nmol} / \mathrm{l})$ compared with patients in group $2(22.1 \pm 6.8 \mathrm{nmol} / \mathrm{l})$. Evaluation of the ROC curve showed that MTXPG4 values below $22.5 \mathrm{nmol} / \mathrm{l}$ corresponded to the absence of the therapeutic effect of MTX. The area under the curve was 0.672 , (Cl 95 $0.536-0.808) ; p=0.022$. Sensitivity - 77\%, specificity - $53.3 \%$.

Conclusion: For effective treatment of RA patients, it is necessary to administer such doses of MTX so that the achieved level of MTXPG4 in erythrocytes is not less than $22.5 \mathrm{nmol} / \mathrm{l}$.

Disclosure of Interests: Galina Gridneva: None declared, Yury Muraviev: None declared, Alexander Lila Speakers bureau: Pfizer, Inc., MSD, Novartis, AbbVie Inc., Celgen Corporation, Biocad, Janssen, UCB, Inc., Natalia Baymeeva: None declared

DOI: 10.1136/annrheumdis-2019-eular.1260

\begin{tabular}{|l|l|}
\hline FRI0152 & METHOTREXATE TREATMENT PATTERNS IN \\
& ADVANCED THERAPY-NAÏVE PATIENTS WITH \\
& RHEUMATOID ARTHRITIS: CLINICAL \\
& CHARACTERISTICS AND OUTCOMES OF PATIENTS IN \\
& THE CORRONA REGISTRY
\end{tabular}

Leslie Harrold ${ }^{1}$, Heather J. Litman ${ }^{2}$, Jacqueline O'brien², Hua Feng², Casey Schlacher ${ }^{3}$, Namita Tundia ${ }^{3} .{ }^{1}$ University of Massachusetts Medical School, Worcester, United States of America; ${ }^{2}$ Corrona, LLC, Waltham, United States of America; ${ }^{3}$ AbbVie Inc., North Chicago, United States of America

Background: Methotrexate (MTX) is one of the most commonly used drugs in the treatment of rheumatoid arthritis (RA). Some patients may discontinue MTX therapy due to lack of efficacy or intolerance and may or may not restart MTX. There is a need to better understand the patterns of MTX use, the characteristics of these patients, and how the patterns of use are related to outcomes.

Objectives: To assess patterns of MTX use in a clinical practice setting, describe baseline demographic and clinical characteristics for groups defined by patterns of MTX use, and assess the association of patterns of MTX use with clinical outcomes and side effects during the 2 years after MTX initiation.

Methods: This observational study included patients from the US Corrona RA registry who initiated MTX from 01 October 2001 to 31 October 2018, were biologic/targeted synthetic disease-modifying antirheumatic drug (bDMARD/tsDMARD)-naïve and did not start bDMARD/tsDMARD through 2 years of follow-up. Patients were divided into 3 cohorts: those who discontinued and restarted MTX, those who discontinued without restarting MTX and those who persisted on MTX. Descriptive statistics were used to evaluate patient demographics and disease activity at MTX initiation and side effects during follow-up. Changes in clinical outcomes from baseline to 2 years were calculated for all groups. Differences in outcomes were assessed using Kruskal-Wallis one-way analysis of variance for continuous or ordinal-dependent variables and chi-square test for categorical variables.

Results: Among 785 MTX initiators, 34 (4.3\%) discontinued/restarted MTX $174(22.2 \%)$ discontinued MTX, and $577(73.5 \%)$ persisted on MTX within the 2-year follow-up period. Overall, mean age was 59.7 years; $72.7 \%$ were female; mean duration of RA was 4.8 years; and $52.9 \%$ were conventional synthetic DMARD-naïve. Generally, in patients who discontinued/ restarted, discontinued, or persisted on MTX, those who discontinued/ restarted therapy had more comorbidities at MTX initiation: hypertension $(35.3 \%, 32.8 \%$, or $29.3 \%$, respectively), malignancy $(14.7 \%$, $9.2 \%$, or $8.7 \%$, respectively), chronic obstructive pulmonary disease $(10.0 \%, 3.9 \%$, $1.9 \%$, respectively), or asthma $(5.0 \%, 4.7 \%$, or $2.9 \%$, respectively). At end of follow-up, mean Clinical Disease Activity Index (CDAI) was 15.6, 10.1 , and 8.8 for those who discontinued/restarted, discontinued, and persisted, respectively. Disease activity according to CDAl improved during the 2-year follow-up for all 3 groups, but less improvement was observed in those who discontinued/restarted MTX (Table). Overall, the most common side effects while on MTX therapy were elevated liver enzymes $(65.4 \%)$ and fatigue $(43.1 \%)$. Patients who discontinued/restarted MTX vs those who persisted had higher rates of hair loss (35.3\% vs $18.9 \%$ ), loss of appetite $(32.4 \%$ vs $17.3 \%)$ stomach pain (26.5\% vs $14.6 \%$ ), mouth sores $(20.6 \%$ vs $16.3 \%)$, diarrhœa $(11.8 \%$ vs $9.5 \%)$, and myelosuppression $(8.8 \%$ vs $2.1 \%)$.

Conclusion: More than $26 \%$ of patients who initiated MTX therapy either discontinued and did not restart or discontinued and restarted therapy during 2 years of follow-up. Patients who discontinued/restarted MTX therapy had less improvement in disease activity, experienced more side 